(C) The Author(s), 2021. Published by Cambridge University Press on behalf of The Nutrition Society. This is an Open Access article, distributed under the terms of the Creative Commons Attribution licence (http://creativecommons.org/licenses/by/4.0/), which permits unrestricted re-use, distribution, and reproduction in any medium, provided the original work is properly cited.

\title{
Understanding the role of smoking and chronic excess alcohol consumption on reduced caloric intake and the development of sarcopenia
}

\author{
Konstantinos Prokopidis ${ }^{1}$ and Oliver C. Witard ${ }^{2} *$ \\ ${ }^{1}$ Department of Metabolism, Digestion and Reproduction, Faculty of Medicine, Imperial College London, White City, London, UK \\ ${ }^{2}$ Centre for Human and Applied Physiological Sciences, School of Basic and Medical Biosciences, Faculty of Life Sciences and \\ Medicine, King's College London, London, UK
}

\section{Abstract}

This narrative review provides mechanistic insight into the biological link between smoking and/or chronic excess alcohol consumption, and increased risk of developing sarcopenia. Although the combination of excessive alcohol consumption and smoking is often associated with ectopic adipose deposition, this review is focused on the context of a reduced caloric intake (leading to energy deficit) that also may ensue due to either lifestyle habit. Smoking is a primary cause of periodontitis and chronic obstructive pulmonary disease that both induce swallowing difficulties, inhibit taste and mastication, and are associated with increased risk of muscle atrophy and mitochondrial dysfunction. Smoking may contribute to physical inactivity, energy deficit via reduced caloric intake, and increased systemic inflammation, all of which are factors known to suppress muscle protein synthesis rates. Moreover, chronic excess alcohol consumption may result in gut microbiota dysbiosis and autophagyinduced hyperammonemia, initiating the up-regulation of muscle protein breakdown and down-regulation of muscle protein synthesis via activation of myostatin, AMPK and REDD1, and deactivation of IGF-1. Future research is warranted to explore the link between oral healthcare management and personalised nutrition counselling in light of potential detrimental consequences of chronic smoking on musculoskeletal health outcomes in older adults. Experimental studies should investigate the impact of smoking and chronic excess alcohol consumption on the gut-brain axis, and explore biomarkers of smoking-induced oral disease progression. The implementation of behavioural change interventions and health policies regarding smoking and alcohol intake habits may mitigate the clinical and financial burden of sarcopenia on the healthcare system.

Key words: Smoking: Alcohol: Ageing: Muscle protein metabolism: Undernutrition

(Received 21 October 2020; revised 4 March 2021; accepted 19 May 2021; accepted manuscript published online 24 May 2021)

\section{Introduction}

Smoking and chronic excessive alcohol consumption are lifestyle choices that represent major risk factors for comorbidities in older adults, including heart (fatty liver) disease, cirrhosis, alcoholic hepatitis, chronic obstructive pulmonary disease (COPD), and various forms of cancer $^{(1)}$. According to latest statistics, $28 \%$ and $14 \%$ of adult men and women in the UK, respectively, consume more than the recommended 14 units of alcohol per week, with $38 \%$ between the ages of 55 and 64 years $^{(2)}$. Moreover, $14.4 \%$ of adults are classified as smokers and, combined with excessive alcohol consumption, this demographic accounts for $>800000$ of hospital admissions per year ${ }^{(3)}$. Importantly, a higher prevalence of excessive alcohol consumption has been reported in smokers than non-smokers, thus imposing a double burden on public health $^{(1)}$.

The worldwide population over the age of 65 years is rapidly increasing, with figures projected to exceed $2 \cdot 1$ billion by 2050 . Age-related morbidities involving the musculoskeletal system are increasingly common, and include type 2 diabetes, cancer cachexia and osteoporosis. These morbidities may be perpetuated by sarcopenia, which describes the age-related decline in skeletal muscle mass and function, and which serves as a precursor for a decrease in independence, frailty and overall mortality during older age ${ }^{(4)}$. Sarcopenia may begin as early as the fifth decade of life. It is estimated that more than 50 million people worldwide are sarcopenic, and this figure is expected to rise to 200 million by $2050^{(5)}$. This trajectory clearly presents an alarming clinical and financial challenge to the healthcare sector ${ }^{(5)}$. To this end, there is considerable interest in understanding effective lifestyle interventions to promote musculoskeletal health in our ageing population $^{(6)}$; however, the impact of smoking and/or chronic excessive alcohol consumption on the development of sarcopenia has received relatively limited attention.

The potential link between chronic excessive alcohol consumption and/or systemic smoking and sarcopenia risk is clearly multi-factorial, context-specific and not fully understood.

* Corresponding author: Oliver C. Witard; email: oliver.witard@kcl.ac.uk 
Systemic tobacco smoking and alcohol consumption may contribute to ectopic fat accumulation in skeletal muscle ${ }^{(7)}$ and the development of non-alcoholic fatty liver disease, often manifesting in a state of obesity. Accordingly, skeletal muscle fat infiltration (myosteatosis) may increase lipotoxicity and the subsequent release of excess reactive oxygen species (ROS) and low-grade inflammation (i.e. increased interleukin-6 (IL-6) and tumour necrosis factor (TNF)- $\alpha$ secretion), leading to a disruption in glucose homeostasis ${ }^{(8)}$. Myosteatosis also may interfere with energy metabolism by contributing to skeletal muscle insulin resistance and gut microbiota dysbiosis via intramuscular fat deposition ${ }^{(9)}$. Moreover, in terms of muscle protein metabolism, systemic inflammation and oxidative stress are associated with muscle fibre atrophy via the impaired stimulation of muscle protein synthesis (MPS) and accelerated rates of muscle protein breakdown $(\mathrm{MPB})^{(10)}$. In addition, and perhaps paradoxically to the increased risk of ectopic adipose deposition when smoking and excess alcohol intake is combined, both lifestyle choices may indirectly lead to a reduced caloric intake, undernutrition and an energy deficit ${ }^{(11)}$, all of which exhibit detrimental implications for muscle protein metabolism and have the potential to increase risk of sarcopenia ${ }^{(12)}$. Thus, given that smoking and chronic excess alcohol consumption are lifestyle choices that continue over many years or decades, understanding the impact of both lifestyle habits on muscle protein metabolism is important for maintaining musculoskeletal health across the lifespan.

Multiple physiological mechanisms are understood to underpin sarcopenia, including hypogonadism, altered oral and gastrointestinal health, increased pro-inflammatory cytokines, motor unit impairments and skeletal muscle insulin resistance leading to mitochondrial dysfunction ${ }^{(4)}$. In addition, muscle anabolic resistance, which describes the age-related impairment in the stimulation of MPS in response to anabolic stimuli (i.e. amino acid provision and exercise/physical activity), alongside the age-related suppression of appetite and reduced energy expenditure $^{(4)}$ all contribute to sarcopenia risk. A key factor that contributes to the development of any catabolic condition is a chronic state of energy deficit ${ }^{(12)}$. Dietary guidelines for the management of sarcopenia typically target specific macronutrient intakes to support the remodelling of skeletal muscle proteins ${ }^{(13)}$, alongside the emerging roles of dietary fibre ${ }^{(14)}$, omega-3 fatty acids $^{(15)}$ and specific individual amino acids (i.e. leucine) ${ }^{(16)}$ in regulating muscle protein metabolism ${ }^{(17)}$. More recent interest has focused on the impact of lifestyle factors on sarcopenia risk, with studies measuring changes in muscle protein metabolism in response to physical inactivity ${ }^{(18-20)}$, muscle disuse/immobilisation $^{(21,22)}$ and low protein consumption ${ }^{(23)}$ in older adults. Given the high prevalence rates of smoking and chronic alcohol intake patterns in middle/older adult populations, understanding the metabolic impact of these lifestyle habits (both individually and when combined) on muscle protein metabolism offers an important consideration to combat risk of sarcopenia. While we acknowledge that smoking and chronic excess alcohol consumption are often associated with ectopic adipose deposition ${ }^{(24,25)}$, the primary aim of this narrative review is to critically evaluate the mechanistic link between smoking and chronic excess alcohol consumption and sarcopenia risk in the specific context of a reduced caloric intake (leading to energy deficit) that also may ensue due to either lifestyle habit. We highlight the direct and indirect biological pathways that underpin the link between smoking and/or chronic excessive alcohol consumption and muscle protein metabolism in this population.

\section{Smoking, undernutrition and sarcopenia}

At the metabolic level, a key contributor of skeletal muscle catabolism leading to muscle atrophy is a chronic period of negative energy balance ${ }^{(12)}$. This metabolic state predisposes a catabolic environment with the loss of both fat and lean tissue mass ${ }^{(26-28)}$. A negative energy balance has been shown to suppress the activation of insulin-like growth factor 1 (IGF-1) and the mechanistic target of rapamycin complex 1 (mTORC1) cascade, leading to impaired rates of MPS and increased transcription of muscle atrophy-related genes, including myostatin and ubiquitin-proteasome system (UPS) that up-regulate $\mathrm{MPB}^{(12)}$. The stimulation of MPS is an energetically expensive process, and thus, maintenance of muscle mass during an energy deficit is metabolically challenging ${ }^{(12)}$. Previous studies have revealed associations between smoking and lower body mass index (BMI). Moreover, pre-clinical weight loss studies have demonstrated reductions in BMI to be associated with increased smoking duration ${ }^{(29-32)}$. Hence, a clinical link appears to exist between smoking status, undernutrition and subsequent risk of sarcopenia.

The causal mechanisms that underpin the impact of smoking on appetite, energy balance and muscle protein metabolism are detailed in Fig. 1. The anorexic effects of smoking primarily relate to the nicotine content of cigarettes ${ }^{(33)}$. Previous studies demonstrate that food intake is modulated by $\beta 2-, \beta 3-, \beta 4-, \alpha 3-$, $\alpha 4-, \alpha 5-, \alpha 6-$ and $\alpha 7$-nicotinic acetylcholine receptor (nAChR) subtypes $^{(34-38)}$, which act primarily in the arcuate nucleus of the ventral hypothalamus and are responsible for the control of feeding patterns and energy expenditure ${ }^{(39,40)}$. A change in energy balance with smoking occurs via neurons and appetite-related hormones in the central and peripheral nervous system that are stimulated by $\mathrm{nAChR}$ receptor subtypes. Specifically, nicotine administration stimulates proopiomelanocortin and cocaine- and amphetamine-regulated transcript ${ }^{(41,42)}$, but down-regulates feeding-promoting neuropeptide $\mathrm{Y}$ and Agouti-related protein ${ }^{(43,44)}$. In addition, decreased food cravings during smoking are associated with lower acetylated ghrelin and enhanced leptin levels as regulatory hormones of energy balance ${ }^{(45-49)}$. Ghrelin receptors are expressed in the nucleus accumbens and the ventral tegmental area leading to dopamine release, which exhibits reward properties ${ }^{(50,51)}$. It follows that nAChR receptors decrease the food rewarding properties associated with activation of mesolimbic dopamine neurons, leading to a decreased appetite of sweet and calorically dense foods ${ }^{(52-57)}$. Although dopamine receptors are stimulated via nicotine administration, studies have demonstrated a reduced nicotine-induced reward in obese individuals, suggesting a greater potential of appetite-suppressive effects on food palatability in leaner individuals ${ }^{(58,59)}$. Given the addictive properties of nicotine and difficulties associated with long-term smoking abstinence, smoking has the potential to facilitate a chronic period of energy 
Understanding the role of smoking and chronic excess alcohol consumption on reduced caloric intake and the development of sarcopenia 199

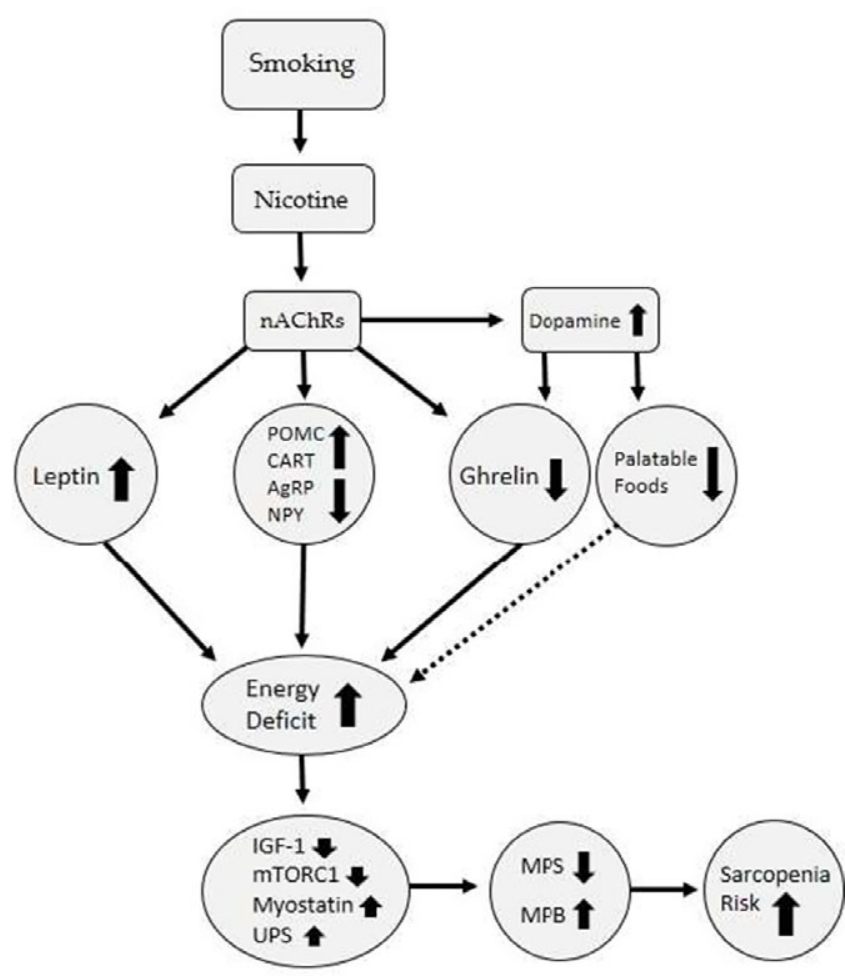

Fig. 1. Proposed mechanisms underpinning the impact of smoking and nicotine administration on appetite and undernutrition. CART, cocaine- and amphetamine-regulated transcript; IGF-1, insulin-like growth factor 1; MPB, muscle protein breakdown; MPS, muscle protein synthesis; mTORC1, mammalian target of rapamycin complex 1; nAChRs, nicotinic acetylcholine receptors; NPY, neuropeptide Y; POMC, pro-opiomelanocortin; UPS, ubiquitin-proteasome system. $\uparrow$ Solid arrows denote a direct impact; $\mathbf{\Lambda}$ broken arrows denote an indirect impact; $\boldsymbol{\uparrow}$ indicates increase; $\boldsymbol{\downarrow}$ indicates decrease.

deficit $^{(60)}$. Therefore, a reduced appetite due to smoking may lead to a negative energy balance, corresponding to a muscle catabolic response and an increased risk of muscle atrophy.

Smoking also has been associated with a decrease in Bifidobacterium levels and short-chain fatty acids in the gut microbiota, suggesting that smoking may modify microbial composition $^{(61)}$. Bifidobacterium and short-chain fatty acids are considered beneficial for metabolic health by improving microbiome diversity, insulin sensitivity and the expression of pro-inflammatory cytokines, which are essential for optimal skeletal muscle function ${ }^{(14,62-65)}$. Accordingly, the interactions between nicotine administration and the gut-brain axis are important in regulating appetite, given that smoking may suppress energy intake and contribute to an energy deficit and subsequent skeletal muscle loss. Also noteworthy is the notion that the gut-brain axis is a complex mechanism that is regulated by multiple factors such as genetics, psychological, social and environmental state, nicotine metabolism, and the gut microbiota. This observation indicates a complex and multifaceted relationship between smoking and suppressed food consumption ${ }^{(66,67)}$. Moving forward, future human studies are warranted to investigate the relationship between smoking and gastrointestinal hormone regulation to quantify the impact of smoking on muscle protein metabolism and the regulation of muscle mass with advancing age.

\section{Smoking, oral health and muscle loss}

The deterioration of oral health and consequential dental implications are restrictive for food choice and mastication, leading to reduced dietary intakes from meat, fruits and vegetables. These commonly consumed food sources are major sources of highquality protein, vitamins, minerals and dietary fibre ${ }^{(68-72)}$. Smoking is associated with poor oral health, which may lead to decreased oral function (e.g. swallowing problems, loss of taste) and compromised food intake, both of which may contribute to an increased incidence of sarcopenia and frailty ${ }^{(73-77)}$. Smoking also may contribute to periodontitis, which manifests as a progressive deterioration of the teeth periodontium leading to chewing difficulties ${ }^{(78)}$. In vivo human studies indicate the relationship between poor oral health and periodontitis ${ }^{(78,79)}$ may lead to increases in mitochondrially derived $\operatorname{ROS}^{(80)}$ and lipopolysaccharide (LPS) levels caused by Porphyromonas gingivalis bacterial infection $^{(81,82)}$ and has been associated with a substantive decline in handgrip strength ${ }^{(83)}$. Accordingly, the cumulative response of periodontitis may be exacerbated with age, enhancing the development of sarcopenia through malnutrition, increased oxidative stress and inflammatory cytokine activation involved in the impaired stimulation of MPS $^{(84-90)}$. In summary, oral health complications associated with smoking may indirectly accelerate the incidence of sarcopenia, highlighting the necessity to maintain oral hygiene during chronic periods of smoking ${ }^{(91)}$. Moving forward, a multidisciplinary approach, including dental professionals, dietitians, nutritionists and geriatricians, may provide optimal oral health care management (i.e. prosthodontic rehabilitation) and personalised dietary counselling, combined with follow-up treatments ${ }^{(91,92)}$. Longitudinal studies are required to characterise biomarkers of the progression of periodontitis and understand the risk factors associated with this condition ${ }^{(93)}$.

\section{Smoking, chronic obstructive pulmonary disease and muscle wasting}

Smoking is considered the primary cause of COPD, which is characterised by restricted airflow and pulmonary complications ${ }^{(94)}$. The prevalence of COPD is associated with an increased risk of sarcopenia via systemic inflammation, lower BMI, osteoporosis, cachexia and skeletal muscle weakness ${ }^{(95-100)}$. Interestingly, COPD may result in limited exercise capacity through enhanced muscle fatigue and may exacerbate lean mass and bone mineral density losses with advancing age ${ }^{(101-103)}$. Accordingly, previous studies have reported a decline in quadriceps muscle mass and isokinetic muscle function in COPD patients compared with healthy age-matched controls ${ }^{(104-107)}$. This observation is consistent with previous research that observed reductions in type I and IIA muscle fibres, impaired mitochondrial function and skeletal muscle oxidative capacity in COPD patients, leading to age-related decrements of muscle mass and strength ${ }^{(108-111)}$. However, it is worth noting that smoking per se may not be the causal factor in muscle fibre atrophy and instead may serve to contribute to muscle disuse and its subsequent consequences ${ }^{(112)}$. 
Studies also suggest an association between COPD and hypogonadism, which may be attributed to physical inactivity, weight reduction and systemic inflammation ${ }^{(113,114)}$. The gradual weight loss that is experienced in COPD patients may lead to an increased catabolic response of respiratory muscles and elevated levels of inflammatory cytokines, which exacerbates changes in body composition ${ }^{(115-117)}$. Although COPD is a potential contributor of sarcopenia, tobacco smoking may independently lead to impaired rates of MPS, increased oxidative stress, myostatin expression and cytokine production in skeletal muscle $\mathrm{e}^{(118-120)}$. Consistent with this notion, a series of studies demonstrate an up-regulation of the UPS of MPB, as reflected by increased gene expression of skeletal muscle growth inhibitors such as muscle atrophy F-Box (MAFbx/atrogin-1), muscle RING finger-1 (MuRF1) and myostatin through the deactivation of the Akt pathway in smokers versus non-smokers ${ }^{(119,121,122)}$. Accordingly, it has been proposed that increased oxidative stress from aldehydes, carbon monoxide, ROS and reactive nitrogen species circulate to the skeletal muscle and activate the p38 and ERK mitogen-activated protein kinase (MAPK), and the nuclear factor $\kappa \mathrm{B}(\mathrm{NF}-\kappa \mathrm{B})$ signalling pathway ${ }^{(123-125)}$. This overexpression of MAPK may up-regulate the muscle-specific E3 ubiquitin ligases and lead to a greater inflammatory response and up-regulation of MPB in smokers, thus accelerating risk of sarcopenia ${ }^{(126-128)}$.

\section{Chronic alcohol consumption and skeletal muscle dysfunction}

Akin to tobacco smoking, evidence exists that excessive alcohol consumption exacerbates sarcopenia risk via direct and indirect mechanisms related to impaired skeletal muscle protein metabolism ${ }^{(129-131)}$, as depicted in Fig. 2.

The association between excessive alcohol consumption and gut microbiota dysbiosis is supported by studies that reveal hepatic and intestinal inflammation in humans ${ }^{(132-135)}$. In particular, reduced Bacteroidetes and Lactobacillus, and increased Proteobacteria, Fusobacteria and Bacilli species are common in chronic alcoholics versus healthy patients ${ }^{(133,135)}$. Conversely, positive outcomes in the microbiome also have been highlighted by moderate red wine consumption, potentially due to its polyphenol content and prebiotic benefits ${ }^{(136,137)}$. Alcohol-induced microbial dysbiosis has the potential to cause or progress liver diseases and facilitate further disruptions in liver metabolism ${ }^{(138-140)}$. Hepatic damage that results from altered microbial composition, increased intestinal permeability and circulating endotoxins (e.g. LPS) may progressively lead to subsequent systemic inflammation and insulin resistance, which are common in sarcopenic populations ${ }^{(141-145)}$. Increased circulating LPS levels may lead to greater pro-inflammatory cytokine secretion, inducing muscle atrophy and mitochondrial dysfunction, which is prevalent in muscle-wasting conditions ${ }^{(146)}$. It follows that skeletal muscle dysfunction may be mediated by a combination of cellular senescence, the up-regulation of UPS, unfolding of MPB regulators, and FoXO1/3 signalling pathways ${ }^{(147)}$.
It has been proposed that a variety of catabolic mechanisms are impacted by chronic exposure to ethanol and contribute to skeletal muscle atrophy ${ }^{(148)}$. Increased ethanol intake $(>40 \mathrm{~g} / \mathrm{d}$; 7-14 drinks per week in women-men, respectively) may cause impaired ureagenesis and hepatocyte injury, stimulating high ammonia concentrations ${ }^{(149-155)}$. This observation may result in hyperammonemia, which dysregulates skeletal muscle proteostasis $^{(156-158)}$. The increase in skeletal muscle ammonia uptake is suggested to up-regulate autophagy and impair MPS, thus increasing sarcopenia $\operatorname{risk}^{(159,160)}$. Using a rodent model, excess administration of ethanol suppressed protein synthesis rates at the whole-body (-41\%) and skeletal muscle (-75\%) level ${ }^{(161)}$, and resulted in the up-regulation of muscle-specific E3 ligases, atrogin-1 and MuRF1, leading to muscle proteolysis $^{(162)}$. Furthermore, alcohol consumption following concurrent exercise may impair cellular homeostasis and trigger intramyocellular apoptosis, and subsequently inhibit postexercise rates of $\operatorname{MPS}^{(163)}$. Similarly, there is evidence that alcohol consumption inhibits MPS and up-regulates UPS and AMP-activated protein kinase (AMPK) phosphorylation during exercise recovery ${ }^{(164-168)}$ and following muscle injury and immobilisation ${ }^{(169,170)}$. Accordingly, alcohol consumption may inhibit muscle adaptations to resistance training in population groups (i.e. athletes) that aim to enhance muscle mass and function. Importantly, these observations also likely apply to older adult binge drinkers, who are consequently at greater risk of sarcopenia than social drinkers ${ }^{(130,171)}$. Moreover, the inhibitory effect of systemic inflammation on rates of MPS may be additive when excessive alcohol consumption and smoking are combined. Although human trials are lacking to evaluate the direct effect of combined tobacco and ethanol intake on skeletal muscle protein metabolism, oral flora modifications from aldehydes (i.e. acetaldehyde) via both smoking and alcohol exposure may enhance hyperammonemia and autophagy, and the expression of muscle myostatin, MAFbx and down-regulatory mechanisms of MPS ${ }^{(119,172)}$. Future work also is necessary to compare the combined impact of excess alcohol consumption and electronic cigarettes (i.e. vaping) or conventional cigarette smoking on muscle protein metabolism and musculoskeletal health outcomes in older adults.

Multiple studies have investigated the impact of chronic alcohol consumption on skeletal muscle metabolism using rodent models, and have observed reduced basal rates of MPS $^{(173-175)}$. Both in vivo ${ }^{(156,176)}$ and in vitro ${ }^{(175,177,178)}$ studies have demonstrated that alcohol consumption impairs the muscle protein synthetic machinery via decreased activation of mTORC1, ribosomal protein S6 kinase 1 (S6K1) and eukaryotic translation initiation factor 4E-binding protein 1 (4E-BP1). This down-regulation of mTORC-1 signalling with chronic alcohol consumption may be initiated via increased AMPK, REDD1 (regulated in development and DNA damage responses 1) and myostatin activation ${ }^{(158,179)}$, as well as decreased plasma and muscle insulin-like growth factor I (IGF-I), which is known to activate the mTORC1 signalling pathway ${ }^{(175,180)}$. In summary, there is accumulating evidence that inhibiting mTORC1-related mechanisms with an increase in habitual alcohol intake 
Understanding the role of smoking and chronic excess alcohol consumption on reduced caloric intake and the development of sarcopenia 201

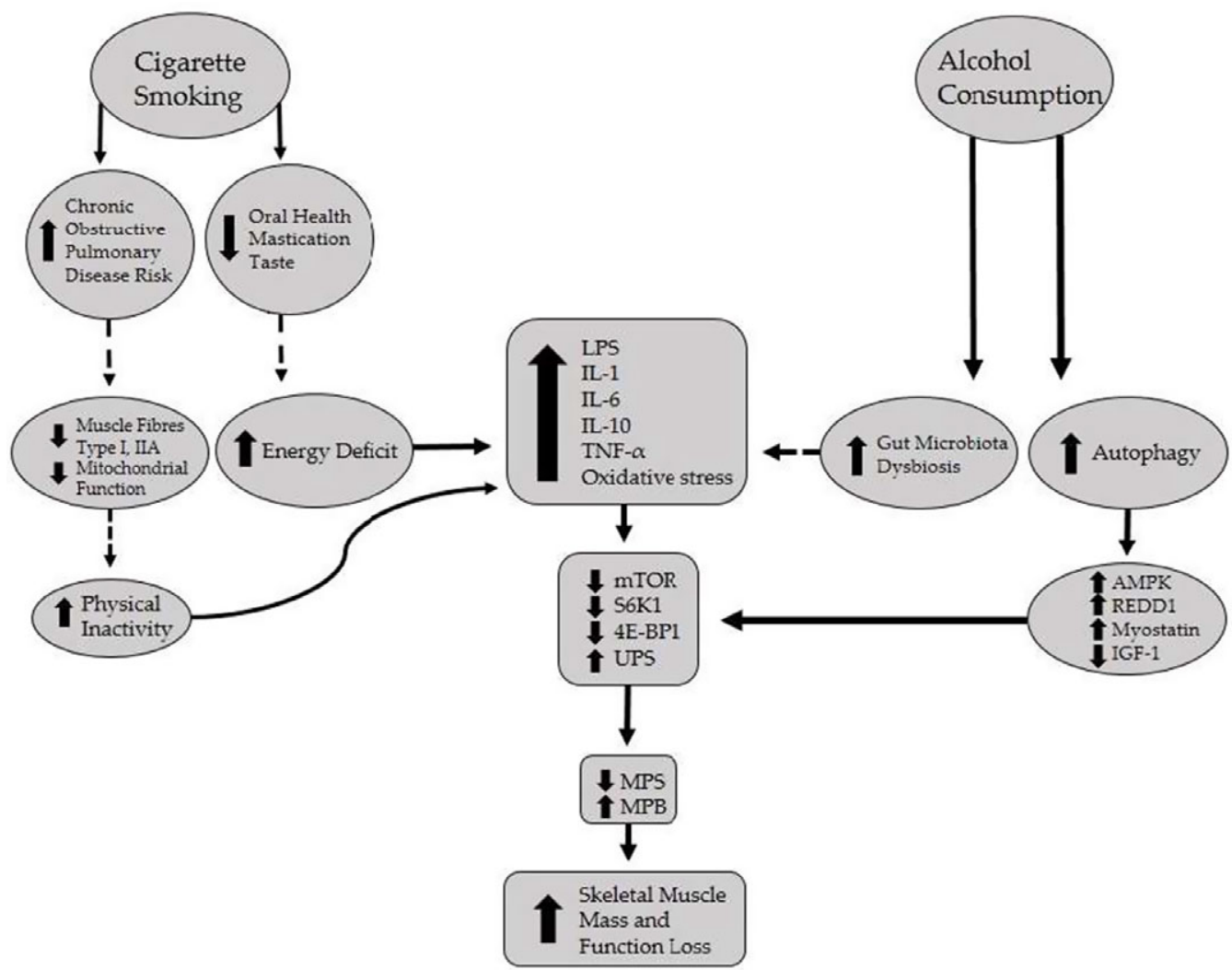

Fig. 2. Indirect and direct mechanisms that may underpin the decline in muscle mass and function with smoking and excessive alcohol consumption. 4E-BP1, eukaryotic translation initiation factor 4E-binding protein 1; AMPK, AMP-activated protein kinase; IGF-1, insulin-like growth factor 1; IL-1, interleukin 1; IL-6, interleukin 6; IL-10, interleukin 10; MPB, muscle protein breakdown; MPS, muscle protein synthesis; mTOR, mammalian target of rapamycin; REDD1, regulated in development and DNA damage responses 1 ; S6K1, ribosomal protein $\mathrm{S} 6$ kinase 1; TNF- $\alpha$, tumour necrosis factor-alpha; UPS, ubiquitin proteasome system. $\uparrow$ Solid arrows denote a direct impact; $\mathbf{A}$ broken arrows denote an indirect impact; $\boldsymbol{\uparrow}$ indicates increase; $\downarrow$ indicates decrease.

attenuates MPS. However, follow-up pre-clinical human trials are warranted to definitively determine the impact of chronic excess alcohol consumption on skeletal muscle protein metabolism and subsequent onset of sarcopenia.

\section{Conclusions}

Accumulating evidence suggests that health implications of smoking and chronic excessive alcohol consumption extend to the musculoskeletal system, as mediated by the down-regulation of metabolic pathways that regulate muscle protein metabolism and subsequent increased risk of sarcopenia. Chronic use of tobacco products may contribute to undernutrition through oral health and dopamine receptor dysfunction and, combined with systemic inflammation, may impair basal rates of MPS. Similarly, excessive alcohol consumption is linked to the impaired stimulation of MPS, primarily due to contraindications that occur upstream in the mTORC1 signalling pathway that are driven by the expression of pro-inflammatory cytokines. Both smoking and chronic alcohol consumption also lead to metabolic damage through underlying conditions such as periodontitis, COPD and liver diseases, which may act synergistically to inhibit skeletal muscle function. Given that chronic smoking and alcohol consumption is common in Western society, these lifestyle habits have the potential to accelerate age-related muscle atrophy and sarcopenia.

\section{Author contributions}

K.P. conceived and wrote the initial draft of the manuscript; O.C.W. reviewed and revised the manuscript.

This review received no external funding.

There are no conflicts of interest.

\section{References}

1. Verplaetse TL \& McKee SA (2017) An overview of alcohol and tobacco/nicotine interactions in the human laboratory. $A m \mathrm{~J}$ Drug Alcohol Abuse 43, 186-196.

2. NHS (2019) Statistics on alcohol, England - 2019. https:// digital.nhs.uk/data-and-information/publications/statistical/ statistics-on-alcohol/2019 (accessed October 2020).

3. NHS (2019) Statistics on smoking, England - 2019. https:// digital.nhs.uk/data-and-information/publications/statistical/ statistics-on-smoking/statistics-on-smoking-england-2019 (accessed October 2020).

4. Cruz-Jentoft AJ, Bahat G, Bauer J, et al. (2019) Sarcopenia: revised European consensus on definition and diagnosis. Age Ageing 48, 16-31.

5. Cruz-Jentoft AJ, Baeyens JP, Bauer JM, et al. (2010) Sarcopenia: European consensus on definition and diagnosis. Age and Ageing 39, 412-423.

6. Witard OC, Mcglory C, Hamilton DL, et al. (2016) Growing older with health and vitality: a nexus of physical activity, exercise and nutrition. Biogerontology 17, 529-546. 
7. Stuart CE, Hons B, Ko J, et al. (2020) Implications of tobacco smoking and alcohol consumption on ectopic fat deposition in individuals after pancreatitis. Pancreas 49, 924-934.

8. Dewidar B, Kahl S, Pa K, et al. (2020) Metabolic liver disease in diabetes - from mechanisms to clinical trials. Metabolism 111S, 154299

9. Altajar S \& Baffy G (2020) Skeletal muscle dysfunction in the development and progression of nonalcoholic fatty liver disease. J Clin Transl Hepatol 8, 414-423.

10. Balage M, Averous J, Rémond D, et al. (2010) Presence of lowgrade inflammation impaired postprandial stimulation of muscle protein synthesis in old rats. $J$ Nutr Biochem 21, 325-331.

11. Ross LJ, Wilson M, Banks M, et al. (2012) Prevalence of malnutrition and nutritional risk factors in patients undergoing alcohol and drug treatment. Nutrition 28, 738-743.

12. Carbone JW, McClung JP, Pasiakos SM, et al. (2012) Skeletal muscle responses to negative energy balance: effects of dietary protein. Adv Nutr 3, 119-126.

13. Rom O, Kaisari S, Aizenbud D, et al. (2012) Lifestyle and sarcopenia - etiology, prevention and treatment. Rambam Maimonides Med J 3, e0024.

14. Frampton J, Murphy KG, Frost G, et al. (2020) Short-chain fatty acids as potential regulators of skeletal muscle metabolism and function. Nat Metab 2, 840-848.

15. Mcglory C, Gorissen SHM, Kamal M, et al. (2019) Omega-3 fatty acid supplementation attenuates skeletal muscle disuse atrophy during two weeks of unilateral leg immobilization in healthy young women. FASEB $J \mathbf{3 3}$, 4586-4597.

16. Mitchell WK, Wilkinson DJ, Phillips BE, et al. (2016) Human skeletal muscle protein metabolism responses to amino acid nutrition. Adv Nutr An Int Rev J 7, 828S-838S.

17. Trumbo P, Schlicker S, Yates AA, et al. (2002) Dietary reference intakes for energy, carbohydrate, fiber, fat, fatty acids, cholesterol, protein and amino acids. J Am Diet Assoc 102, 1621-1630.

18. Oikawa SY, Holloway TM, Phillips SM, et al. (2019) The impact of step reduction on muscle health in aging: protein and exercise as countermeasures. Front Nutr 6, 1-11.

19. De Mello RGB, Dalla Corte RR, Gioscia J, et al. (2019) Effects of physical exercise programs on sarcopenia management, dynapenia, and physical performance in the elderly: a systematic review of randomized clinical trials. J Aging Res 2019, 1959486.

20. Howlett N, Trivedi D, Troop NA, et al. (2019) Are physical activity interventions for healthy inactive adults effective in promoting behavior change and maintenance, and which behavior change techniques are effective? A systematic review and meta-analysis. Transl Behav Med 9, 147-157.

21. Breen L, Stokes KA, Churchward-Venne TA, et al. (2013) Two weeks of reduced activity decreases leg lean mass and induces "anabolic resistance" of myofibrillar protein synthesis in healthy elderly. J Clin Endocrinol Metab 98, 2604-2612.

22. English KL \& Paddon-Jones D (2010) Protecting muscle mass and function in older adults during bed rest. Curr Opin Clin Nutr Metab Care 13, 34-39.

23. Bauer J, Biolo G, Cederholm T, et al. (2013) Evidence-based recommendations for optimal dietary protein intake in older people: a position paper from the PROT-AGE study group. J Am Med Dir Assoc 14, 542-559.

24. Kato A, Li Y, Ota A, et al. (2019) Smoking results in accumulation of ectopic fat in the liver. Diabetes, Metab Syndr Obes Targets Ther 12, 1075-1080.

25. Steiner JL \& Lang CH (2017) Alcohol, adipose tissue and lipid dysregulation. Biomolecules 7, 16.
26. Beaudart C, Sanchez-Rodriguez D, Locquet M, et al. (2019) Malnutrition as a strong predictor of the onset of sarcopenia. Nutrients 11, 1-13.

27. Hunter GR, Singh H, Carter SJ, et al. (2019) Sarcopenia and its implications for metabolic health. J Obes 2019, 1-10.

28. Sousa-Santos AR, Afonso C, Borges N, et al. (2019) Factors associated with sarcopenia and undernutrition in older adults. Nutr Diet 76, 604-612.

29. Audrain-Mcgovern J \& Benowitz NL (2011) Cigarette smoking, nicotine, and body weight. Clin Pharmacol Ther 90, 164-168.

30. Blauw LL, Boon MR, Rosendaal FR, et al. (2015) Smoking is associated with increased resting energy expenditure in the general population: the NEO study. Metabolism 64, 1548-1555.

31. Chiolero A, Faeh D, Paccaud F, et al. (2008) Consequences of smoking for body weight, body fat distribution, and insulin resistance. Am J Clin Nutr 87, 801-809.

32. MacKay DF, Gray L, Pell JP, et al. (2013) Impact of smoking and smoking cessation on overweight and obesity: Scotlandwide, cross-sectional study on 40,036 participants. BMC Public Health 13, 348.

33. Jo YH, Talmage DA, Role LW, et al. (2002) Nicotinic receptormediated effects on appetite and food intake. J Neurobiol $\mathbf{5 3}$, 618-632.

34. Gotti C, Zoli M, Clementi F, et al. (2006) Brain nicotinic acetylcholine receptors: native subtypes and their relevance. Trends Pharmacol Sci 27, 482-491.

35. Dani JA \& Bertrand D (2007) Nicotinic acetylcholine receptors and nicotinic cholinergic mechanisms of the central nervous system. Annu Rev Pharmacol Toxicol 47, 699-729.

36. McFadden KL, Cornier M-A, Tregellas JR, et al. (2014) The role of alpha-7 nicotinic receptors in food intake behaviors. Front Psychol 5, 553.

37. Picciotto MR \& Mineur YS (2014) Molecules and circuits involved in nicotine addiction: the many faces of smoking. Neuropharmacology 76, 545-553.

38. Sanjakdar SS, Maldoon PP, Marks MJ, et al. (2015) Differential roles of $\alpha 6 \beta 2 *$ and $\alpha 4 \beta 2 *$ neuronal nicotinic receptors in nicotine- and cocaine-conditioned reward in mice. Neuropsychopharmacology 40, 350-360.

39. Sainsbury A \& Zhang L (2010) Role of the arcuate nucleus of the hypothalamus in regulation of body weight during energy deficit. Mol Cell Endocrinol 316, 109-119.

40. Mineur YS, Abizaid A, Rao Y, et al. (2011) Nicotine decreases food intake through activation of POMC neurons. Science 332, 1330-1332.

41. Martínez De Morentin PB, Whittle AJ, Fernø J, et al. (2012) Nicotine induces negative energy balance through hypothalamic AMP-activated protein kinase. Diabetes 61, 807-817.

42. Chen H, Hansen MJ, Jones JE, et al. (2006) Cigarette smoke exposure reprograms the hypothalamic neuropeptide $\mathrm{Y}$ axis to promote weight loss. Am J Respir Crit Care Med 173, 1248-1254.

43. Fornari A, Pedrazzi P, Lippi G, et al. (2007) Nicotine withdrawal increases body weight, neuropeptide Y and Agoutirelated protein expression in the hypothalamus and decreases uncoupling protein-3 expression in the brown adipose tissue in high-fat fed mice. Neurosci Lett 411, 72-76.

44. Hussain T, Al-Daghri NM, Al-Attas OS, et al. (2012) Plasma neuropeptide $\mathrm{Y}$ levels relate cigarette smoking and smoking cessation to body weight regulation. Regul Pept 176, 22-27.

45. Kroemer NB, Wuttig F, Bidlingmaier M, Zimmermann US, Smolka MN et al. (2015) Nicotine enhances modulation of food-cue reactivity by leptin and ghrelin in the ventromedial prefrontal cortex. Addict Biol 20, 832-344. 
46. Kokkinos A, Tentolouris N, Kyriakaki E, et al. (2007) Differentiation in the short- and long-term effects of smoking on plasma total ghrelin concentrations between male nonsmokers and habitual smokers. Metabolism 56, 523-527.

47. Koopmann A, Bez J, Lemenager T, et al. (2015) Effects of cigarette smoking on plasma concentration of the appetiteregulating peptide ghrelin. Ann Nutr Metab 66, 155-161.

48. Li MD \& Kane JK (2003) Effect of nicotine on the expression of leptin and forebrain leptin receptors in the rat. Brain Res $\mathbf{9 9 1}$ 222-231.

49. Wittekind DA, Kratzsch J, Mergl R, et al. (2019) Higher fasting ghrelin serum levels in active smokers than in former and never-smokers. World J Biol Psychiatry 21, 748-756.

50. Han JE, Frasnelli J, Zeighami Y, et al. (2018) Ghrelin enhances food odor conditioning in healthy humans: an fMRI study. Cell Rep 25, 2643-2652.

51. Jerlhag E \& Engel JA (2011) Ghrelin receptor antagonism attenuates nicotine-induced locomotor stimulation, accumbal dopamine release and conditioned place preference in mice. Drug Alcohol Depend 117, 126-131.

52. Kenny PJ \& Markou A (2006) Nicotine self-administration acutely activates brain reward systems and induces a long-lasting increase in reward sensitivity. Neuropsychopharmacology 31, 1203-1211.

53. Jerlhag E, Egecioglu E, Dickson SL, et al. (2008) Alphaconotoxin MII-sensitive nicotinic acetylcholine receptors are involved in mediating the ghrelin-induced locomotor stimulation and dopamine overflow in nucleus accumbens. Eur Neuropsychopharmacol 18, 508-518.

54. Blum K, Liu Y, Shriner R, et al. (2012) Reward circuitry dopaminergic activation regulates food and drug craving behavior. Curr Pharm Des 17, 1158-1167.

55. Zoli M \& Picciotto MR (2012) Nicotinic regulation of energy homeostasis. Nicotine Tob Res 14, 1270-1290.

56. Criscitelli K \& Avena NM (2016) The neurobiological and behavioral overlaps of nicotine and food addiction. Prev Med (Baltim) 92, 82-89.

57. Stojakovic A, Espinosa EP, Farhad OT, et al. (2017) Effects of nicotine on homeostatic and hedonic components of food intake. J Endocrinol 235, R13-R31.

58. Blendy JA, Strasser A, Walters CL, et al. (2005) Reduced nicotine reward in obesity: cross-comparison in human and mouse. Psychopharmacology (Berl) 180, 306-315.

59. Rupprecht LE, Donny EC, Sveda AF, et al. (2015) Obese smokers as a potential subpopulation of risk in tobacco reduction policy. Yale J Biol Med 88, 289-294.

60. al'Absi M, Lemieux A, Hodges JS, et al. (2019) Circulating orexin changes during withdrawal are associated with nicotine craving and risk for smoking relapse. Addict Biol 24, $743-753$

61. Tomoda K, Kubo K, Asahara T, et al. (2011) Cigarette smoke decreases organic acids levels and population of bifidobacterium in the caecum of rats. J Toxicol Sci 36, 261-266.

62. Chambers ES, Byrne CS, Morrison DJ, et al. (2019) Dietary supplementation with inulin-propionate ester or inulin improves insulin sensitivity in adults with overweight and obesity with distinct effects on the gut microbiota, plasma metabolome and systemic inflammatory responses: a randomised cross-over t. Gut 68, 1430-1438.

63. Delzenne NM, Knudsen C, Beaumont M, et al. (2019) Contribution of the gut microbiota to the regulation of host metabolism and energy balance: a focus on the gut-liver axis. Proc Nutr Soc 78, 319-328.

64. Hiippala K, Jouhten H, Ronkainen A, et al. (2018) The potential of gut commensals in reinforcing intestinal barrier function and alleviating inflammation. Nutrients 10, 988.
65. Le Chatelier E, Nielsen T, Qin J, et al. (2013) Richness of human gut microbiome correlates with metabolic markers. Nature 500, 541-546.

66. Hu T, Yang Z, Li MD, et al. (2018) Pharmacological effects and regulatory mechanisms of tobacco smoking effects on food intake and weight control. J Neuroimmune Pharmacol 13, 453-466.

67. Nakajima M, Fukami T, Yamanaka H, et al. (2006) Comprehensive evaluation of variability in nicotine metabolism and CYP2A6 polymorphic alleles in four ethnic populations. Clin Pharmacol Ther 80, 282-297.

68. Brennan DS, Spencer AJ, Roberts-Thomson KF, et al. (2008) Tooth loss, chewing ability and quality of life. Qual Life Res 17, 227-235.

69. Hung HC, Colditz G, Joshipura KJ, et al. (2005) The association between tooth loss and the self-reported intake of selected CVD-related nutrients and foods among US women. Community Dent Oral Epidemiol 33, 167-173.

70. Gil-Montoya JA, de Mello ALF, Barrios R, et al. (2015) Oral health in the elderly patient and its impact on general wellbeing: a nonsystematic review. Clin Interv Aging 10, 461-467.

71. Golpasand Hagh L, Zakavi F, Ansarifar S, et al. (2013) Association of dental caries and salivary sIgA with tobacco smoking. Aust Dent J 58, 219-223.

72. Stenman U, Ahlqwist M, Björkelund C, et al. (2012) Oral health-related quality of life - associations with oral health and conditions in Swedish 70-year-old individuals. Gerodontology 29, 1-7.

73. Bakri NN, Tsakos G, Masood M, et al. (2018) Smoking status and oral health-related quality of life among adults in the United Kingdom. Br Dent J 225, 153-158.

74. Steffl M, Bohannon RW, Petr M, et al. (2015) Relation between cigarette smoking and sarcopenia: meta-analysis. Physiol Res 64, 419-426.

75. Tanaka T, Takahashi K, Hirano H, et al. (2018) Oral frailty is a risk factor for physical frailty and mortality in communitydwelling elderly. J Gerontol Ser A Biol Sci Med Sci $\mathbf{7 3}$, 1661-1667.

76. Zhu Y \& Hollis JH (2014) Tooth loss and its association with dietary intake and diet quality in American adults. J Dent $\mathbf{4 2}$, 1428-1435.

77. Murakami M, Hirano H, Watanabe Y, et al. (2015) Relationship between chewing ability and sarcopenia in Japanese community-dwelling older adults. Geriatr Gerontol Int $\mathbf{1 5}$, 1007-1012.

78. Lertpimonchai A, Rattanasiri S, Arj-Ong Vallibhakara S, et al. (2017) The association between oral hygiene and periodontitis: a systematic review and meta-analysis. Int Dent $J \mathbf{6 7}$, 332-343.

79. Hirotomi T, Yoshihara A, Yano M, et al. (2002) Longitudinal study on periodontal conditions in healthy elderly people in Japan. Community Dent Oral Epidemiol 30, 409-417.

80. Bullon P, David M, Luis J, et al. (2011) Mitochondrial dysfunction promoted by Porphyromonas gingivalis lipopolysaccharide as a possible link between cardiovascular disease and periodontitis. Free Radic Biol Med 50, 1336-1343.

81. Wang PL \& Ohura K (2002) Porphyromonas gingivalis lipopolysaccharide signaling in gingival fibroblasts-CD14 and toll-like receptors. Crit Rev Oral Biol Med 13, 132-142.

82. Bullon P, Cordero MD, Quiles JL, et al. (2012) Autophagy in periodontitis patients and gingival fibroblasts: unraveling the link between chronic diseases and inflammation. $B M C$ Med 10, 122 .

83. Hamalainen P, Rantanen T, Keskinen M, et al. (2004) Oral health status and change in handgrip strength over a 5-year period in 80-year-old people. Gerodontology 21, 155-160. 
84. Barreiro E, Peinado VI, Galdiz JB, et al. (2010) Cigarette smoke-induced oxidative stress: a role in chronic obstructive pulmonary disease skeletal muscle dysfunction. Am J Respir Crit Care Med 182, 477-488.

85. Borges I, Machado Moreira EA, Filho DW, et al. (2007) Proinflammatory and oxidative stress markers in patients with periodontal disease. Mediators Inflamm 2007, 1-5.

86. Castreján-Pérez RC, Borges-Yãez SA, Gutiérrez-Robledo LM, et al. (2012) Oral health conditions and frailty in Mexican community-dwelling elderly: a cross sectional analysis. $B M C$ Public Health 12, 773.

87. D'Aiuto F, Nibali L, Parkar M, et al. (2010) Oxidative stress, systemic inflammation, and severe periodontitis. J Dent Res $\mathbf{8 9}$, $1241-1246$

88. Lamster IB, Asadourian L, Del Carmen T, et al. (2000) The aging mouth: differentiating normal aging from disease. Periodontol 72, 96-107.

89. Neves CDC, Lacerda ACR, Lage VKS, et al. (2016) Oxidative stress and skeletal muscle dysfunction are present in healthy smokers. Braz J Med Biol Res 49, 1-7.

90. Takahashi M, Maeda K, Wakabayashi H, et al. (2018) Prevalence of sarcopenia and association with oral healthrelated quality of life and oral health status in older dental clinic outpatients. Geriatr Gerontol Int 18, 915-921.

91. Azzolino D, Passarelli PC, De Angelis P, et al. (2019) Poor oral health as a determinant of malnutrition and sarcopenia. Nutrients 11, 1-17.

92. Zenthofer A, Rammelsberg P, Cabrera T, et al. (2015) Prosthetic rehabilitation of edentulism prevents malnutrition in nursing home residents. Int J Prostbodont 28, 198-200.

93. Tonetti MS, Bottenberg P, Conrads G, et al. (2017) Dental caries and periodontal diseases in the ageing population: call to action to protect and enhance oral health and well-being as an essential component of healthy ageing - consensus report of group 4 of the joint EFP/ORCA workshop on the boundaries between caries and periodontal diseases. J Clin Periodontol 44, S135-S144.

94. Roca J, Vargas C, Cano I, et al. (2014) Chronic obstructive pulmonary disease heterogeneity: challenges for health risk assessment, stratification and management. J Transl Med 12, 1-11.

95. Andrianopoulos V, Wouters EFM, Pinto-Plata VM, et al. (2015) Prognostic value of variables derived from the six-minute walk test in patients with COPD: results from the ECLIPSE study. Respir Med 109, 1138-1146.

96. Barbar MPF, Carpagnan GE, Spanevellol A, et al. (2007) Inflammation, oxidative stress and systemic effects in mild chronic obstructive disease. Int I Immunopathol Pharmacol 20, 753-763

97. Franco CB, Paz-Filho G, Gomes PE, et al. (2009) Chronic obstructive pulmonary disease is associated with osteoporosis and low levels of vitamin D. Osteoporos Int 20, 1881-1887.

98. Gan WQ, Man SFP, Senthilselvan A, et al. (2004) Association between chronic obstructive pulmonary disease and systemic inflammation: a systematic review and a meta-analysis. Thorax 59, 574-580.

99. Jagoe RT \& Engelen MPKJ (2003) Muscle wasting and changes in muscle protein metabolism in chronic obstructive pulmonary disease. Eur Respir J 22, 52-63.

100. Van Den Borst B, Koster A, Yu B, et al. (2011) Is age-related decline in lean mass and physical function accelerated by obstructive lung disease or smoking? Thorax 66, 961-969.

101. Byun MK, Cho EN, Chang J, et al. (2017) Sarcopenia correlates with systemic inflammation in COPD. Int JCOPD 12, 669-675.

102. Munhoz da Rocha Lemos Costa T, Costa FM, Jonasson TH, et al. (2018) Borba VZC. Body composition and sarcopenia in patients with chronic obstructive pulmonary disease. Endocrine 60, 95-102.

103. Eliason G, Abdel-Halim S, Arvidsson B, et al. (2009) Physical performance and muscular characteristics in different stages of COPD. Scand J Med Sci Sport 19, 865-870.

104. Clark CJ, Cochrane LM, Mackay E, et al. (2000) Erratum: skeletal muscle strength and endurance in patients with mild COPD and the effects of weight training. Eur Respir J 15, 816.

105. Allaire J, Maltais F, Leblanc P, et al. (2002) Lipofuscin accumulation in the vastus lateralis muscle in patients with chronic obstructive pulmonary disease. Muscle Nerve 25, 383-389.

106. Allaire J, Maltais F, Doyon JF, et al. (2004) Peripheral muscle endurance and the oxidative profile of the quadriceps in patients with COPD. Thorax 59, 673-678.

107. Crul T, Testelmans D, Spruit MA, et al. (2010) Gene expression profiling in vastus lateralis muscle during an acute exacerbation of COPD. Cell Physiol Biochem 25, 491-500.

108. Agustí AGN, Sauleda J, Miralles C, et al. (2002) Skeletal muscle apoptosis and weight loss in chronic obstructive pulmonary disease. Am J Respir Crit Care Med 166, 485-489.

109. Gosker HR, van Mameren H, van Dijk PJ, et al. (2002) Skeletal muscle fibre-type shifting and metabolic profile in patients with chronic obstructive pulmonary disease. Eur Respir J 19, 617-625.

110. Meyer A, Zoll J, Charles AL, et al. (2013) Skeletal muscle mitochondrial dysfunction during chronic obstructive pulmonary disease: central actor and therapeutic target. Exp Physiol $\mathbf{9 8}$, 1063-1078.

111. Krüger K, Dischereit G, Seimetz M, et al. (2015) Time course of cigarette smoke-induced changes of systemic inflammation and muscle structure. Am J Physiol Lung Cell Mol Physiol 309, L119-L128.

112. Degens H \& Alway SE (2006) Control of muscle size during disuse, disease, and aging. Int J Sports Med 27, 94-99.

113. Karadag F, Ozcan H, Karul AB, et al. (2009) Sex hormone alterations and systemic inflammation in chronic obstructive pulmonary disease. Int J Clin Pract 63, 275-281.

114. Laghi F, Langbein WE, Antonescu-Turcu A, et al. (2005) Respiratory and skeletal muscles in hypogonadal men with chronic obstructive pulmonary disease. Am J Respir Crit Care Med 171, 598-605.

115. Lainscak M, von Haehling S, Doehner W, et al. (2011) Body mass index and prognosis in patients hospitalized with acute exacerbation of chronic obstructive pulmonary disease. J Cachexia Sarcopenia Muscle 2, 81-86.

116. Makarevich AE \& Lemiasheuskaya S (2015) Dynamics of body composition in male patients during chronic obstructive pulmonary disease (COPD) development. Pneumonol Alergol Pol 83, 424-430.

117. Puente-Maestu L, Pérez-Parra J, Godoy R, et al. (2009) Abnormal mitochondrial function in locomotor and respiratory muscles of COPD patients. Eur Respir J 33, 1045-1052.

118. Madani A, Alack K, Richter MJ, et al. (2018) Immuneregulating effects of exercise on cigarette smoke-induced inflammation. J Inflamm Res 11, 155-167.

119. Petersen AMW, Magkos F, Atherton P, et al. (2007) Smoking impairs muscle protein synthesis and increases the expression of myostatin and MAFbx in muscle. Am J Physiol Endocrinol Metab 293, 843-849.

120. Zhang J, Liu Y, Shi J, et al. (2002) Side-stream cigarette smoke induces dose-response in systemic inflammatory cytokine production and oxidative stress. Exp Biol Med 227, 823-829.

121. Doucet M, Russell AP, Léger B, et al. (2007) Muscle atrophy and hypertrophy signaling in patients with chronic obstructive pulmonary disease. Am J Respir Crit Care Med 176, 261-269. 
Understanding the role of smoking and chronic excess alcohol consumption on reduced caloric intake and the development of sarcopenia 205

122. Foletta VC, White LJ, Larsen AE, et al. (2011) The role and regulation of MAFbx/atrogin-1 and MuRFl in skeletal muscle atrophy. Pflugers Arch Eur J Physiol 461, 325-335.

123. Degens H, Gayan-Ramirez G, Van Hees HWH, et al. (2015) Smoking-induced skeletal muscle dysfunction: from evidence to mechanisms. Am J Respir Crit Care Med 191, 620-625.

124. Krüger K, Seimetz M, Ringseis R, et al. (2018) Exercise training reverses inflammation and muscle wasting after tobacco smoke exposure. Am J Physiol Regul Integr Comp Physiol 314, R366-R376.

125. Talhout R, Opperhuizen A, van Amsterdam JGC, et al. (2007) Role of acetaldehyde in tobacco smoke addiction. Eur Neuropsychopharmacol 17, 627-636.

126. Degens H (2010) The role of systemic inflammation in agerelated muscle weakness and wasting: review. Scand J Med Sci Sport 20, 28-38.

127. Liu Q, Xu WG, Luo Y, et al. (2011) Cigarette smoke-induced skeletal muscle atrophy is associated with up-regulation of USP-19 via p38 and ERK MAPKs. J Cell Biochem 112, 2307-2316.

128. Rom O, Kaisari S, Aizenbud D, et al. (2012) Sarcopenia and smoking: a possible cellular model of cigarette smoke effects on muscle protein breakdown. Ann N Y Acad Sci 1259, 47-53.

129. Preedy VR, Adachi J, Ueno Y, et al. (2001) Alcoholic skeletal muscle myopathy: definitions, features, contribution of neuropathy, impact and diagnosis. Eur J Neurol 8, 677-687.

130. Yoo J Il, Ha YC, Lee YK, et al. (2017) High prevalence of sarcopenia among binge drinking elderly women: a nationwide population-based study. BMC Geriatr 17, 114.

131. Pruznak AM, Nystrom J, Lang CH, et al. (2013) Direct central nervous system effect of alcohol alters synthesis and degradation of skeletal muscle protein. Alcohol Alcohol 48, 138-145.

132. Capurso G \& Lahner E (2017) The interaction between smoking, alcohol and the gut microbiome. Best Pract Res Clin Gastroenterol 31, 579-588.

133. Chen Y, Yang F, Lu H, et al. (2011) Characterization of fecal microbial communities in patients with liver cirrhosis. Hepatology 54, 562-572.

134. Leclercq S, Matamoros S, Cani PD, et al. (2014) Intestinal permeability, gut-bacterial dysbiosis, and behavioral markers of alcohol-dependence severity. Proc Natl Acad Sci U S A 111, E4485-E4493.

135. Mutlu EA, Gillevet PM, Rangwala H, et al. (2012) Colonic microbiome is altered in alcoholism. Am $J$ Physiol Gastrointest Liver Physiol 302, G966-G978.

136. Queipo-Ortuno MI, Boto-Ordonez M, Murri M, et al. (2012) Influence of red wine polyphenols and ethanol on the gut microbiota. Am J Clin Nut 95, 1323-1334.

137. Bjørkhaug ST, Aanes H, Neupane SP, et al. (2019) Characterization of gut microbiota composition and functions in patients with chronic alcohol overconsumption. Gut Microbes 10, 663-675.

138. Frazier TH, DiBaise JK, McClain CJ, et al. (2011) Gut microbiota, intestinal permeability, obesity-induced inflammation, and liver injury. J Parenter Enter Nutr 35, 14S-20S.

139. Meroni M, Longo M, Dongiovanni $\mathrm{P}$, et al. (2019) Alcohol or gut microbiota: who is the guilty? Int J Mol Sci 20, 1-22.

140. Schnabl B \& Brenner DA (2014) Interactions between the intestinal microbiome and liver diseases. Gastroenterology 146, 1513-1524.

141. Ghosh S, Lertwattanarak R, De Jesus Garduño J, et al. (2015) Elevated muscle TLR4 expression and metabolic Endotoxemia in human aging. J Gerontol Ser A Biol Sci Med Sci 70, 232-246.

142. Hartmann P, Seebauer CT, Schnabl B, et al. (2015) Alcoholic liver disease: the gut microbiome and liver cross talk. Alcohol Clin Exp Res 39, 763-775.
143. Kakiyama G, Pandak WM, Gillevet PM, et al. (2013) Modulation of the fecal bile acid profile by gut microbiota in cirrhosis. J Hepatol 58, 949-955.

144. Liang H, Hussey SE, Sanchez-Avila A, et al. (2013) Effect of lipopolysaccharide on inflammation and insulin action in human muscle. PLoS One 8, 8-15.

145. Norman K, Pirlich M, Schulzke JD, et al. (2012) Increased intestinal permeability in malnourished patients with liver cirrhosis. Eur J Clin Nutr 66, 1116-1119.

146. Marzetti E, Lorenzi M, Landi F, et al. (2017) Altered mitochondrial quality control signaling in muscle of old gastric cancer patients with cachexia. Exp Gerontol 87, 92-99.

147. Milan G, Romanello V, Pescatore F, et al. (2015) Regulation of autophagy and the ubiquitin-proteasome system by the FoxO transcriptional network during muscle atrophy. Nat Commun 6, $1-14$.

148. Buchmann N, Spira D, König M, et al. (2019) Problematic drinking in the old and its association with muscle mass and muscle function in type II diabetes. Sci Rep $9,1-8$.

149. Aagaard NK, Thøgersen T, Grøfte T, et al. (2004) Alcohol acutely down-regulates urea synthesis in normal men. Alcohol Clin Exp Res 28, 697-701.

150. Dasarathy S, Mookerjee RP, Rackayova V, et al. (2017) Ammonia toxicity: from head to toe? Metab Brain Dis $\mathbf{3 2}$, 529-538.

151. Glavind E, Aagaard NK, Grønbæk H, et al. (2017) Time course of compromised urea synthesis in patients with alcoholic hepatitis. J Hepatol 66, S81.

152. McDaniel J, Davuluri G, Hill EA, et al. (2016) Hyperammonemia results in reduced muscle function independent of muscle mass. Am J Physiol Gastrointest Liver Physiol 310, G163-G170.

153. Qiu J, Tsien C, Thapalaya S, et al. (2012) Hyperammonemiamediated autophagy in skeletal muscle contributes to sarcopenia of cirrhosis. Am J Physiol Endocrinol Metab $\mathbf{3 0 3}$, E983-E993.

154. Stern RA \& Mozdziak PE (2019) Differential ammonia metabolism and toxicity between avian and mammalian species, and effect of ammonia on skeletal muscle: a comparative review. $J$ Anim Physiol Anim Nutr (Berl) 103, 774-785.

155. Jayasekara H, English DR, et al. (2014) Alcohol consumption over time and risk of death: a systematic review and metaanalysis. Am J Epidemiol 179, 1049-1059.

156. Hong-Brown LQ, Frost RA, Lang CH, et al. (2001) Alcohol impairs protein synthesis and degradation in cultured skeletal muscle cells. Alcohol Clin Exp Res 25, 1373-1382.

157. Kant S, Davuluri G, Alchirazi KA, et al. (2019) Ethanol sensitizes skeletal muscle to ammonia-induced molecular perturbations. J Biol Chem 294, 7231-7244.

158. Steiner JL \& Lang CH (2015) Dysregulation of skeletal muscle protein metabolism by alcohol. Am J Physiol Endocrinol Metab 308, E699-E712.

159. Fernandez-Solà J, Preedy VR, Lang CH, et al. (2007) Molecular and cellular events in alcohol-induced muscle disease. Alcobol Clin Exp Res 31, 1953-1962.

160. Thapaliya S, Runkana A, McMullen MR, et al. (2014) Alcoholinduced autophagy contributes to loss in skeletal muscle mass. Autophagy 10, 677-690.

161. Tiernan JM \& Ward LC (1986) Acute effects of ethanol on protein synthesis in the rat. Alcohol Alcohol 21, 171-179.

162. Vary TC, Frost RA, Lang CH, et al. (2008) Acute alcohol intoxication increases atrogin- 1 and MuRF1 mRNA without increasing proteolysis in skeletal muscle. Am J Physiol Integr Comp Physiol 294, 1777-1789.

163. Smiles WJ, Parr EB, Coffey VG, et al. (2016) Protein coingestion with alcohol following strenuous exercise 
attenuates alcohol-induced intramyocellular apoptosis and inhibition of autophagy. Am J Physiol Endocrinol Metab 311, E836-E849.

164. Barnes MJ, Mündel T, Stannard SR, et al. (2010) Post-exercise alcohol ingestion exacerbates eccentric-exercise induced losses in performance. Eur J Appl Physiol 108, 1009-1014.

165. Vingren JL, Hill DW, Buddhadev H, et al. (2013) Postresistance exercise ethanol ingestion and acute testosterone bioavailability. Med Sci Sports Exerc 45, 1825-1832.

166. Parr EB, Camera DM, Areta JL, et al. (2014) Alcohol ingestion impairs maximal post-exercise rates of myofibrillar protein synthesis following a single bout of concurrent training. PLoS One 9, 1-9.

167. Lakićević N (2019) The effects of alcohol consumption on recovery following resistance exercise: a systematic review. J Funct Morphol Kinesiol 4, 41.

168. Vancampfort D, Hallgren M, Vandael H, et al. (2020) Functional exercise capacity in inpatients with alcohol use disorder versus healthy controls: a pilot study. Alcohol 82, 47-52.

169. Dekeyser GJ, Clary CR, Otis JS, et al. (2013) Chronic alcohol ingestion delays skeletal muscle regeneration following injury. Regen Med Res $\mathbf{1}, 2$.

170. Vargas R \& Lang CH (2008) Alcohol accelerates loss of muscle and impairs recovery of muscle mass resulting from disuse atrophy. Alcohol Clin Exp Res 32, 128-137.

171. Silveira EA, De Souza JD, Silva A, et al. (2020) What are the factors associated with sarcopenia-related variables in adult women with severe obesity? Arch Public Heal 78, 71.

172. Husain K, Scott BR, Reddy SK, et al. (2001) Chronic ethanol and nicotine interaction on rat tissue antioxidant defense system. Alcohol 25, 89-97.
173. Korzick DH, Sharda DR, Pruznak AM, et al. (2013) Aging accentuates alcohol-induced decrease in protein synthesis in gastrocnemius. Am J Physiol Regul Integr Comp Physiol 304, R887-R898.

174. Lang CH, Frost RA, Vary TC, et al. (2007) Skeletal muscle protein synthesis and degradation exhibit sexual dimorphism after chronic alcohol consumption but not acute intoxication. Am J Physiol Endocrinol Metab 292, 1497-1507.

175. Lang CH, Pruznak AM, Deshpande N, et al. (2004) Alcohol intoxication impairs phosphorylation of S6K1 and S6 in skeletal muscle independently of ethanol metabolism. Alcohol Clin Exp Res 28, 1758-1767.

176. Hong-Brown LQ, Brown CR, Navaratnarajah M, et al. (2013) Activation of AMPK/TSC2/PLD by alcohol regulates mTORC1 and mTORC2 assembly in C2C12 myocytes. Alcohol Clin Exp Res 37, 1849-1861.

177. Lang CH, Pruznak AM, Nystrom GJ, et al. (2009) Alcoholinduced decrease in muscle protein synthesis associated with increased binding of mTOR and raptor: comparable effects in young and mature rats. Nutr Metab 6, 1-17.

178. Lang CH, Frost RA, Deshpande N, et al. (2003) Alcohol impairs leucine-mediated phosphorylation of 4E-BP1, S6K1, eIF4G, and mTOR in skeletal muscle. Am J Physiol Endocrinol Metab 285, 1205-1215.

179. Lang CH, Frost RA, Svanberg E, et al. (2004) IGF-I/IGFBP-3 ameliorates alterations in protein synthesis, eIF4E availability, and myostatin in alcohol-fed rats. Am J Physiol Endocrinol Metab 286, 916-926.

180. Nguyen VA, Le T, Tong M, et al. (2012) Impaired insulin/IGF signaling in experimental alcohol-related myopathy. Nutrients 4, 1058-1075. 